\title{
Cryptophagus angelesae, a new species of Cryptophagus Herbst, 1792 (Coleoptera: Cryptophagidae) from the Palaearctic Region
}

\author{
José Carlos Otero
}

Otero, J. C. 2015: Cryptophagus angelesae, a new species of Cryptophagus Herbst, 1792 (Coleoptera: Cryptophagidae) from the Palaearctic Region. Entomol. Fennica 26: 88-93.

Cryptophagus angelesae sp. n. from Caucasus is described and illustrated. The differential diagnosis is established in relation to a group of other species of the genus.

J. C. Otero, Departamento de Zoología y Antropología Física, Facultad de Biología, 15782 Santiago de Compostela, Spain; E-mail: josecarlos.otero (a) usc.es

Received 23 February 2015, accepted 23 March 2015

\section{Introduction}

The genus Cryptophagus (Coleoptera: Cryptophagidae) from the Palaearctic Region is still quite unknown in spite of the rather large number of papers published on it (see e.g.: Ljubarsky 1992, 1997, 2000, 2002, 2014, Otero 2011, 2013, Otero \& Johnson 2013). Therefore, this paper aims to contribute to their knowledge in the $\mathrm{Pa}-$ laearctic Region.

This paper is based on material collected by the researchers of the Hungarian Natural History in the Caucasus.

\section{Methods}

Terminology and measurements of the new species follow an earlier paper (Otero \& López 2011). The structures were measured under a Leica M205C stereomicroscope equipped with an analysis system Application Suite.

Abbreviations: $\mathrm{L}=$ length; $\mathrm{WL}=$ width/length ratio; $\mathrm{E}=$ eccentricity of the eyes, which is calcu- lated as width/half of the length (width is measured across the widest part of a line joining the anterior and posterior limit of the eye and length is the maximum length of the eye). $\mathrm{L}$ is used for length in dorsal view, W for width and Ø for diameter; HNHM: Hungarian Natural History Museum, Budapest, Hungary; USC, Universidad de Santiago de Compostela, Spain.

\section{Cryptophagus angelesae Otero sp. $n$.}

Type locality: Avadhara 4330.1' N 4040.1' E, Abkhasia, western Caucasus.

Type material. Holotype $\widehat{\delta}$. Abkhazia, Caucasus occ., Glavnyy Kavkazskiy Khrebet, Ritsinskiy zapovednik, Avadhara, 4330.1' N 4040.1' E, 1,495 m, 23.-26.VII.2011, A. Podlussány \& I. Retezár leg., coll. HNHM. Paratypes, $1 \hat{\sigma}$ and 4 q . . The same locality, date and collector as the holotype. 1 placed in coll. J. C. Otero (coll. USC). $1 \widehat{\delta}$ and $3 \stackrel{+}{\circ}$. Abkhazia, Caucasus occ., Glavnyy Kavkazskiy Khrebet, Pskhusskiy zapovednik, Sanchara Polyana, 
Fig. 1. Cryptophagus angelesae sp. n. - a.

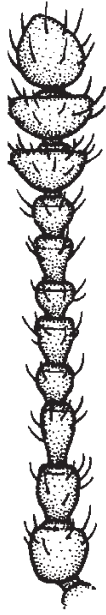

b
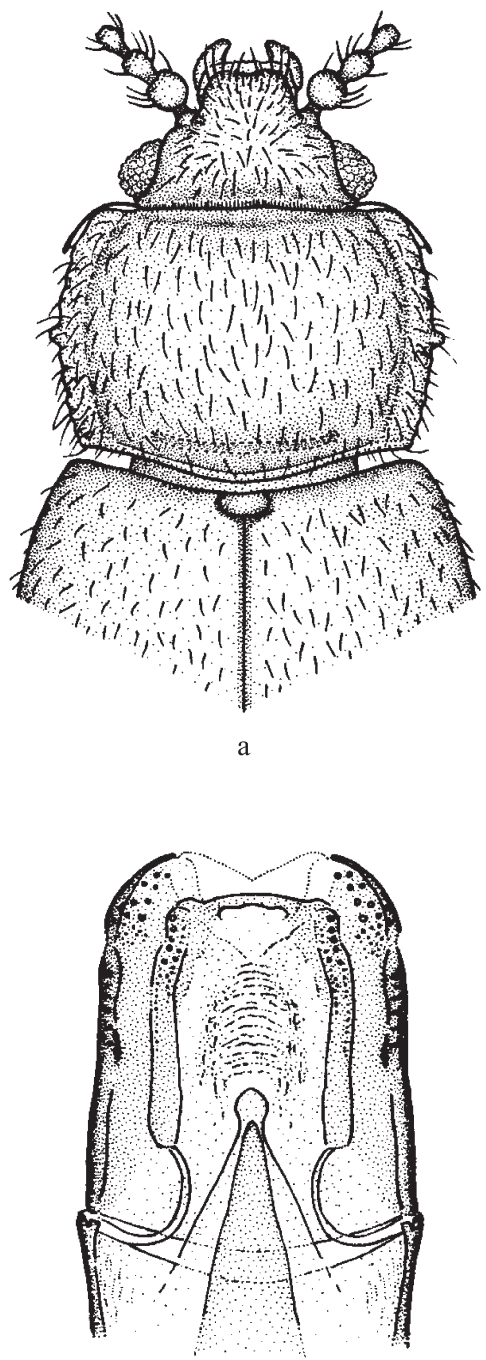

d

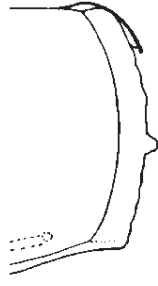

c

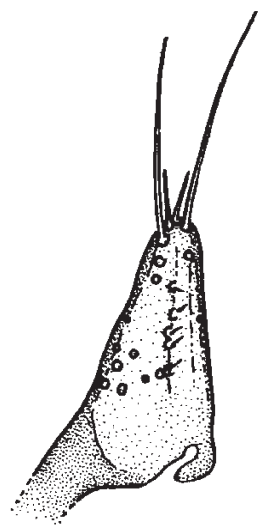

f

General view. - b.Antenna. - c. Pronotum.

- d. Aedeagus. - e.

Sclerotized rods. $-\mathrm{f}$.

Paramere.

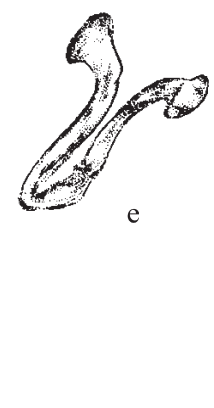

$43^{\circ} 24.7^{\prime} \mathrm{N} 40^{\circ} 51.4^{\prime}$ E, $1,005-1,010 \mathrm{~m}, 17 .-$ 22.VII.2011, A. Podlussány \& I. Retezár leg., coll. HNHM.

Description. Body: Length 2.3-2.5 mm. Body oval, elongated and convex. Colour ferruginous brownish-grey to reddish brownishgrey. Pubescence simple, short $(\mathrm{L}=0.050-0.080$ $\mathrm{mm}$ ), yellowish and flattened. Metathoracic wings absent.

Head: Slightly transverse $(\mathrm{WL}=1.7-1.8)$. Punctuation strong and dense; punctures spaced by a distance shorter than their diameter $(\varnothing=$ 0.026-0.030 mm). Eyes normal, small $(\mathrm{L}=0.146$ $\mathrm{mm}$ ), hemispherical or subhemispherical and protuberant $(E=0.9-1.0)$. Ocular facets smaller $(\varnothing=0.016-0.018 \mathrm{~mm})$ than punctures of head. Antennae short (Fig. 1b) $(\mathrm{L}=0.876 \mathrm{~mm})$, not reaching base of pronotum. First antennal segment thick, cylindrical and as long as $3^{\text {rd }} ; 2^{\text {nd }}$ antennal segment narrower and 1.1 times as long as $1^{\text {st }} ; 4^{\text {th }}, 6^{\text {th }}$ and $8^{\text {th }}$ equally long and 1.4 times as long as $3^{\text {rd }} ; 5^{\text {th }}$ and $7^{\text {th }}$ almost equally long and 1.1 times as long as $6^{\text {th }} ; 9^{\text {th }}$ and $10^{\text {th }}$ strongly transverse.

Pronotum (Fig. 1a, c): Convex, squared or sub-squared $(\mathrm{WL}=1.3-1.4)$ narrowed anteriorly and posteriorly. Small or very small pronotal callosities (1/6-1/7 of the side length), not prolonged anteriorly and hardly protruding from lateral margin of pronotum. Point of callosity present. Cal- 

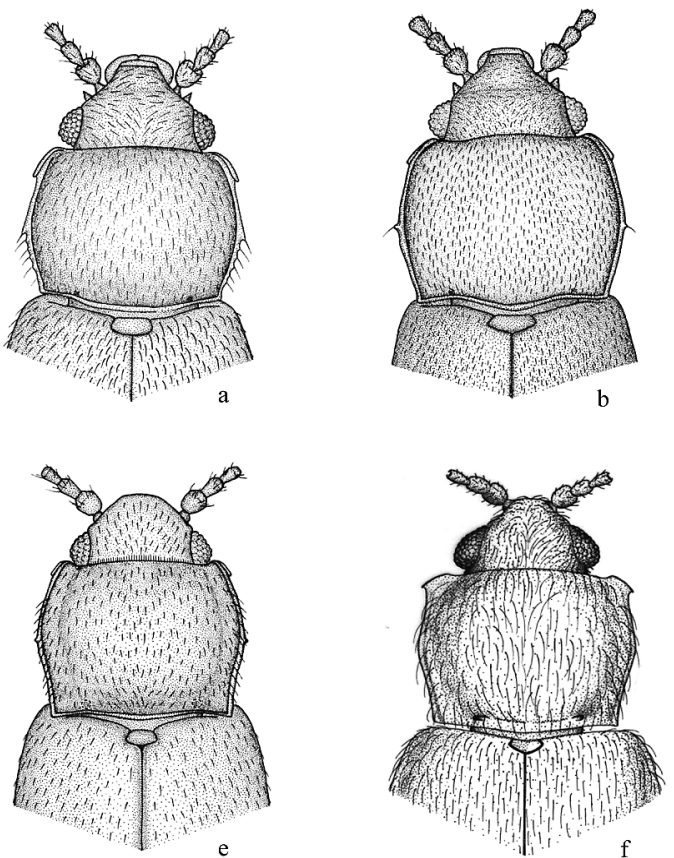
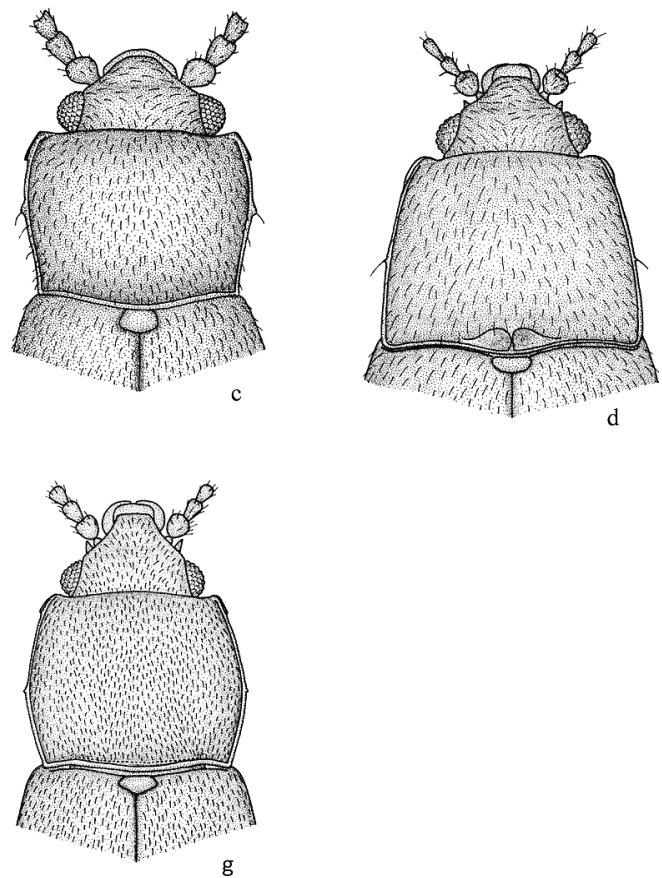

Fig. 2. General view of seven Cryptophagus species. - a. C. axillaris. - b. C. baldensis. - c. C. circassicus.

- d. C. ellipticus. - e. C. gracilis. - f. C. opacosericeus. - g. C. straussi.

losity side not visible dorsally. Glandular pore not visible. Callosity forming a right angle towards end of body and an angle of $38^{\circ}-40^{\circ}$ with body axis. Lateral tooth distinctly protruding, located in middle area of side. Lateral margins straight or slightly concave between callosity and lateral tooth; converging or slightly sinuate from lateral tooth to base. Obtuse posterior angles. Narrow basal groove. Small basal foveae. Punctuation strong and dense; punctures spaced by a distance shorter than their diameter $(\varnothing=0.026-0.030$ $\mathrm{mm})$.

Aedeagus (Fig. 1d): Apex externally rounded and equally wide along its whole length. Preputial sac visible and finely crenulated. Endophallic orifice visible on basal third of aedeagus; apex rounded. Sclerotized rods (Fig. 1e). Triangular parameres (Fig. 1f), twice as long as wide on their base. Scarce pores with or without setae inside. 2-3 apical setae 0.75 times as long as paramere. Base of paramere with a bilateral node covered by its base.

Female: Same external morphological characters as the male.

Biology. Unknown.
Etymology. This species is named in honour of Dra Angeles Romero.

Distribution. Caucasus.

\section{Key to species}

Cryptophagus angelesae sp. n. should be included in "group IV" (see Otero, 2013, p. 63) due to the characteristics of the pronotum: the pronotal callosity front is not dorsally visible; weak rim is not protruding above the lateral margin of pronotum.

1. Pronotum (Fig. 2d) squared or sub-squared $(\mathrm{WL}=1.2$ ) presenting its maximum width on base and narrowing towards apex. Lateral tooth behind middle area of side. Small callosity (1/6 of lateral length). Apex of aedeagus (Fig. 3d) simple. Endophallic orifice visible with dilated apex. Preputial sac visible and finely crenulated. Parameres (Fig. 4d) elongated, twice as long as wide on their base. Base of paramere with bilateral node. Pores with or without setae arranged on base of paramere. $1-2$ apical setae 0.75 times as long 


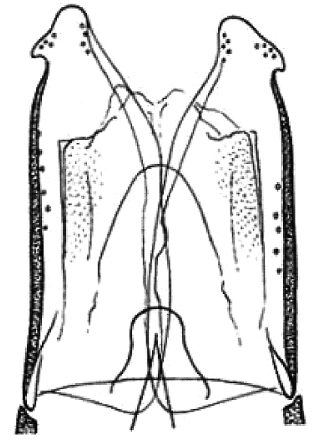

a

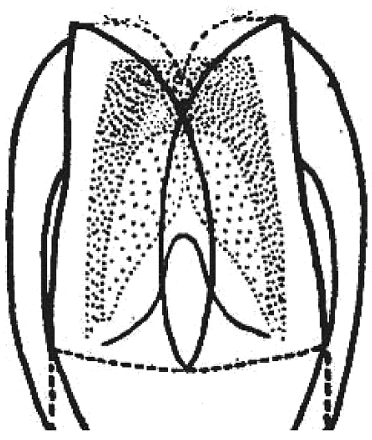

d

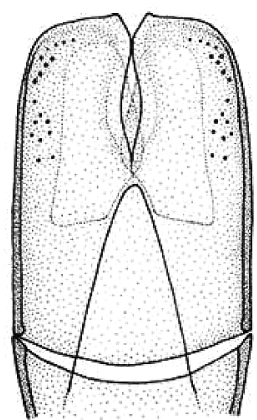

b

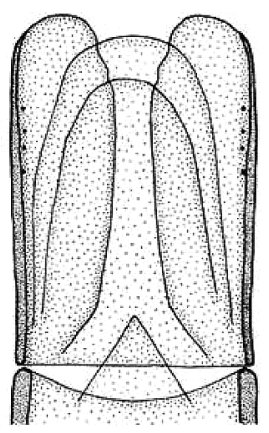

$\mathrm{C}$

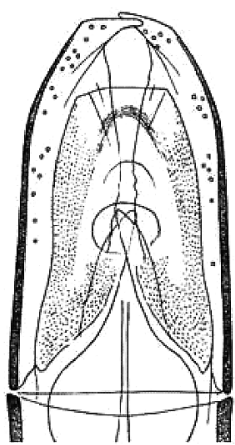

g

Fig. 3. Aedeagus of seven Cryptophagus species. - a. C. axillaris. - b. C. baldensis. - c. C. circassicus. - d. C. ellipticus. - e. C. gracilis. - f. C. opacosericeus. - g. C. straussi.

as paramere. Length: $2.4-2.9 \mathrm{~mm}$. Canary Islands ellipticus Wollaston

- Pronotum squared or sub-squared (WL $=1.3$ 1.4), slightly narrowed anteriorly and posteriorly; maximum width of pronotum at or before midlength

2. Lateral margins of pronotum more or less parallel from callosity to lateral tooth, and convergent in a straight line from callosity to base. Pronotum (Fig. 2c) sub-squared (WL= 1.3-1.4). Lateral tooth located before middle area of side. Metathoracic wings absent. Aedeagus with apex (Fig. 3c) externally rounded and internally straight. Endophallic orifice visible, apically rounded and located in $2 / 3$ of its length. Preputial sac visible. Parameres (Fig. 4c) triangular, twice as long as wide on their base. Base of paramere with a bilateral node. Numerous pores with or with- out setae arranged on basal 2/3 of paramere. Two or three apical setae 0.75 times as long as paramere. Length: 1.7-2.4 mm

circassicus Reitter

- Lateral margins of pronotum, either continuously curved or sinuate

3. Lateral margins of pronotum (Fig. 2a) straight between lateral tooth and base. Pronotum slightly transverse $(\mathrm{WL}=1.3-1.4)$. Lateral tooth prominent and located before midlength. Aedeagus (Fig. 3a) apically dilated. Endophallic orifice apically rounded and located on base of aedeagus. Preputial sac excavated in apex; base of preputial sac invisible. Triangular parameres (Fig. 4a) 1.5 times as long as wide on base. Base of paramere with a bilateral node. Numerous pores with or without setae. 2-3 apical setae, 0.75 times as long 


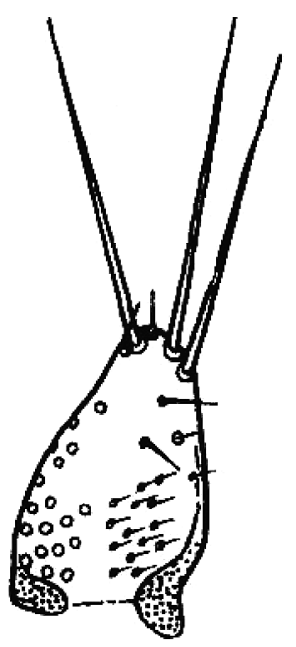

a

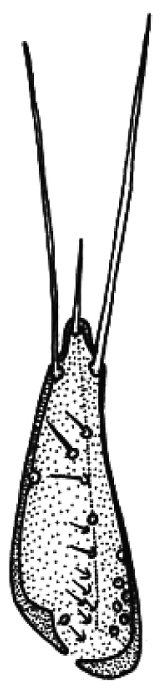

e

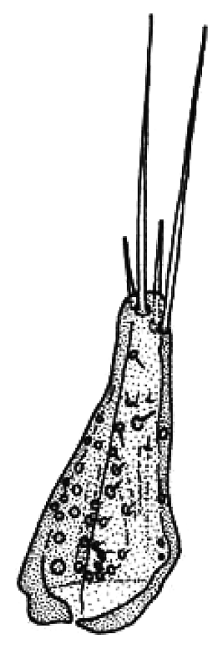

b

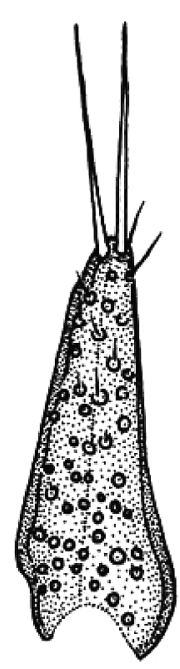

f

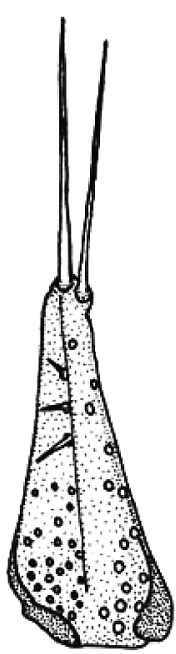

c

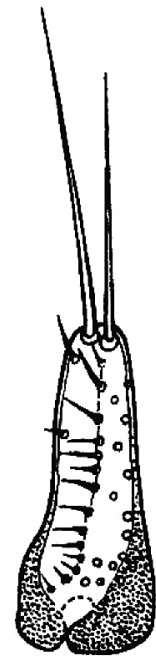

$\mathrm{g}$

Fig. 4. Parameres of seven Cryptophagus species. - a. C. axillaris. - b. C. baldensis. - c. C. circassicus.

- d. C. ellipticus. - e. C. gracilis. - f. C. opacosericeus. - g. C. straussi.

as paramere. Length: $2.0-2.6 \mathrm{~mm}$

axillaris Reitter

- Lateral margins of pronotum slightly sinuate between lateral tooth and base

4

4. Short antennae, not reaching base of pronotum

- Long antennae, surpassing base of pronotum
5. Pronotum (Fig. 2g) sub-squared $(\mathrm{WL}=1.2)$. Lateral tooth prominent and located after midlength. Small callosity (1/7-1/8 of lateral length). Aedeagus apodeme (Fig. 3g) not dilated apically. Apex of aedeagus lobe with a soft protuberance. Endophallic orifice apically pointed. Preputial sac indistinct. Elongated parameres (Fig. 4g), their base almost as 
wide as apex. Basal node reduced, not covered by base of paramere. Numerous pores with or without setae. Two or three apical setae, 0.75 times as long as the paramere. Length:2.2-2.6 mm straussi Ganglbauer

- Pronotum (Fig. 1a) convex, squared or subsquared $(\mathrm{WL}=1.3-1.4)$. Lateral tooth distinctly prominent and located in midlength. Small or very small callosities $(1 / 6-1 / 7$ of side length), not prolonged anteriorly and barely protruding from lateral margin of pronotum. Apex of aedeagus (Fig. 1d) externally rounded and equally wide along its whole length. Preputial sac visible and finely crenulated. Endophallic orifice visible on basal third of aedeagus; rounded apex. Sclerotized rods (Fig. 1e). Triangular parameres (Fig. 1f), twice as long as wide on base. Scarce pores with or without setae inside. 2-3 apical setae, 0.75 times as long as paramere. Base of paramere with a bilateral node covered by its base. Length $2.3-2.5 \mathrm{~mm}$

angelesaesp. $\mathbf{n}$.

6. Lateral tooth located in midlength (Fig. 2e). Lobe of aedeagus (Fig. 3e) rounded. Endophallic orifice clearly visible, located in basal middle area of aedeagus. Preputial sac visible. Parameres (Fig. 4e) elongated, 2.5 times as long as wide on base. Pores with seate arranged on internal half of paramere. Two or three apical setae as long as paramere. Length: $2.0-2.8 \mathrm{~mm}$

gracilis Reitter

- Small or reduced lateral tooth located before middle area of side

7. Metathoracic wings completely developed. Long antennae. Pronotum (Fig. 2f) slightly transverse $(\mathrm{WL}=1.5-1.6)$. Lateral margins straight between callosity and lateral tooth and continuously curved from lateral tooth to base. Lobe of aedeagus (Fig. 3f) rounded. Endophallic orifice visible, apically dilated and located on base of aedeagus. Preputial sac distinct. Sclerotized rods equally wide along their whole length, pointed in the apex and occasionally sinuate. Parameres (Fig. 4f) elongated, twice as long as wide on their base. Base of paramere with a bilateral node. Abundant pores with or without setae inside paramere. Two apical setae 0.75 times as long as the paramere. Length: 2.5-3.6 mm

opacosericeus Reitter

- Metathoracic wings absent. Antennae thick and long. Pronotum (Fig. 2b) slightly transverse $(\mathrm{WL}=1.3)$. Lateral margin concave from callosity to lateral tooth, concave or sinuate from lateral tooth to the base. Apex of aedeagus simple (Fig. 3b); lobe of aedeagus rounded. Endophallic orifice arranged in 2/3 of aedeagus. Endophallic sac indistinct. Parameres (Fig. 4b) 2.0 times as long as wide on their base. Base of paramere with a bilateral node. 2-3 apical setae 0.75 times as long as paramere. Scarce pores with or without setae. Length: 2.4-2.8 mm

baldensis Erichson

Acknowledgements. I would like to thank Dr. Otto Merkl (Hungarian Natural History Museum, Budapest, Hungary) for the loan of the material described in this article

\section{References}

Ljubarsky, G. Yu. 1992: Beetles of the genus Cryptophagus (Coleoptera, Cryptophagidae) from Caucasus. Zoologičeskij Žurnal 71(9): 68-82.

Ljubarsky, G. Yu 1997: Cryptophagidae and Languriidae from India (Coleoptera, Clavicornia). — Entomofauna 18(5): 49-60.

Ljubarsky, G. Yu 2000: New and rare species of the family Cryptophagidae from northern Palaearctic (former USSR) (Coleoptera: Clavicornia). - Russian Entomological Journal 9(4): 321-328.

Ljubarsky, G. Yu 2002: Cryptophaginae (Coleoptera: Cucujoidea: Cryptophagidae): Diagnostics, Arealogy, Ecology. - Moscow University Publisher. Moscow. $421 \mathrm{pp}$.

Ljubarsky, G. Yu 2014: Cryptophagidae (Coleoptera: Clavicornia) from China and adjacent regions. - Russian Entomological Journal 23(1): 19-40.

Otero, J. C. 2011: Coleoptera, Monotomidae, Cryptophagidae. - In: Fauna Iberica, vol. 35. RAMOS, M.A. et al. Museo Nacional de Ciencias Naturales. CSIC. Madrid. 365 pp.

Otero, J. C. 2013: Cryptophaginae (Coleoptera) de la Región Paleártica occidental. - Coleopterological Monographs 4: 1-296.

Otero, J. C. \& Johnson, C. 2013: Species of the genus Cryptophagus Herbst, 1792, belonging to the "dentatus group" (Coleoptera: Cryptophagidae) from the Western Palearctic region. - Entomologica Fennica 24: 81-93.

Otero, J. C. \& López, M. J. 2011: A new species of Cryptophagus Herbst (Coleoptera: Cryptophagidae) from the Iberian Peninsula. — The Coleopterist Bulletin 65(2): 185-188. 